Journal of

Literary Education

\title{
Beginning Readers' Interest in Animal Books: An Analysis of Data Collected from the Children's Choices Project
}

\author{
Interés de los primeros lectores en los libros sobre \\ animales: un análisis de datos recogidos sobre el \\ Proyecto Children's Choices
}

Interés dels lectors primerencs en els llibres sobre animals: un anàlisi de dades recollides sobre el Projecte Children's Choices

\begin{abstract}
Petros Panaou. University of Georgia, USA. ppanaou@uga.edu
\end{abstract}
(iD) https://orcid.org/0000-0001-9265-9942

Eunhye Son. Boise State University, USA. eunhyeson@boisestate.edu,

(iD) https://orcid.org/0000-0002-2115-686X

Maggie Chase. Boise State University, USA. maggiechase@boisestate.edu

(iD) https://orcid.org//0000-0002-5326-0020

Stan Steiner. Boise State University, USA. stansteiner@boisestate.edu

(i) https://orcid.org//0000-0001-9480-7347

How to cite this paper:

Panaou, Petros, Son, Eunhye, Chase, Maggie \& Steiner, Stan (2018) Beginning Readers' Interest in Animal Books: An Analysis of Data Collected from the Children's Choices Project. Journal of Literary Education, (1), 175-192.

https://doi.org/10.7203/JLE.1.12346 